\title{
IUCr-UNESCO OpenLab: 25 editions in 22 countries and counting
}

Michele Zema $^{1}$, Gautam R. Desiraju ${ }^{2}$, Claude Lecomte ${ }^{3}$, Maciej Nalecz ${ }^{4}$, Juste Jean-Paul Ngome Abiaga ${ }^{4}$

${ }^{1}$ International Union Of Crystallography, Chester, United Kingdom, ${ }^{2}$ Indian Institute of Science, Bangalore, India, ${ }^{3}$ University of Lorraine and CNRS, Nancy, France, ${ }^{4}$ UNESCO Division of Science Policy and Capacity-Building, Paris, France E-mail: mz@iucr.org

The concept of a travelling crystallography lab was originally proposed as one of the main activities for the International Year of Crystallography 2014 (IYCr2014), aimed at developing educational activities in parts of the world where crystallography is as yet a poorly developed science, and setting in motion new initiatives in capacity building and international cooperation. This idea converged into the IUCr-UNESCO OpenLab project, consisting of a network of operational crystallographic laboratories and schools to be implemented in selected universities in Africa, Latin America and South-East Asia.

The first OpenLab was held in Karachi, Pakistan in June 2014, in conjunction with the IYCr2014 Summit meeting, followed by implementation in Argentina, Morocco, Ghana, Cambodia, Uruguay, Indonesia, Turkey, Colombia, Mexico, Hong Kong, Vietnam, Turkey, Algeria, Tunisia, Kenya, Senegal, Albania, Bolivia and Cameroon. As of today, a total of 25 OpenLabs have been organized, including second editions for Mexico, Turkey, Vietnam, Cambodia and Uruguay and an OpenFactory, an intensive training workshop held at the headquarters of European companies (Germany and France), where selected earlycareer scientists travelled from many countries to gain hands-on experience with the latest crystallographic equipment. So far, these valuable activities have provided high-level educational opportunities to over a thousand students and young professors.

Key to the success of the project is the synergic combination of the scientific and educational expertise of the IUCr, the diplomatic and educational channels of UNESCO including their network of regional and local offices, and the partnership of crystallographic instrumentation manufacturers. The project is now evolving towards an extended network of collaborations, which include other scientific bodies, such as IUPAP and ICTP. Moreover, it will serve as the main educational tool within the IUPAP-IUCr Lightsources for Africa, the Americas and Middle East Project (LAAMP), which has been awarded a grant under the ICSU Grant Programme 2016-2019. Part of the OpenLab project is also closely connected to the "Crystallography in Africa" initiative of the IUCr, thanks to which crystallographic equipment has recently been or is currently being installed in some sub-Saharan African countries.

Keywords: IYCr2014, education, crystallography schools 